\title{
Gonzalo Bulnes y su Guerra del Pacífico (1911- 1919): historiografía, nacionalismo y usos públicos del pasado en Chile ${ }^{1}$
}

\section{Resumen}

Este artículo examina la obra del historiador Gonzalo Bulnes, Guerra del Pacifico (19111919) y los usos nacionalistas del pasado en Chile a inicios del siglo XX. Mediante un análisis del contexto de producción y circulación de la obra, se abordan el impacto del libro en la opinión pública, los usos políticos y diplomáticos de los que fue objeto el trabajo y cómo Guerra del Pacífico y su argumento se constituyó en un insumo importante para el discurso nacionalista que conceptualizó al conflicto de 1879 como el momento de apogeo de la grandeza nacional en contraposición a la decadencia del presente.

Palabras clave: Gonzalo Bulnes - Guerra del Pacífico - Historiografía - Nacionalismo

\section{Summary}

This article examines the work of the historian Gonzalo Bulnes, Guerra del Pacifico War of the Pacific - (1911-1919) and the nationalist uses of the past at the beginning of the 20th century. Through an analysis of the context of production and circulation of the text, the impact of the book on public opinion, the political and diplomatic uses to which the work was subjected, and how Guerra del Pacifico and his argument became an important element for the nationalist discourse that conceptualized the conflict of 1879 as the height of national greatness as opposed to the decadence of the present.

Keywords: Gonzalo Bulnes - War of the Pacific - Historiography - Nationalism

1 Esta investigación forma parte del Proyecto Fondecyt Regular 1201399, El imaginario de la "Esparta americana": nacionalismo y memoria colectiva en torno a la Guerra del Pacifico, 1879-1929; y contó con el apoyo financiero de la Vicerrectoría de Investigación y Doctorados de la Universidad San Sebastián, proyectoVRIDFAI20/03.

* Universidad San Sebastián. E mail: gabriel.cid@uss.cl 


\section{Introducción: historiografía, usos del pasado y nacionalismo}

El 17 de agosto de 1936 fallecía en Santiago de Chile el historiador Gonzalo Bulnes, a la avanzada edad de 84 años. La vida del prolífico escritor, político y diplomático fue interrumpida cuando estaba trabajando en una biografía sobre José Miguel Carrera. ${ }^{2}$ En el multitudinario funeral que se realizó en las calles de la capital, un contingente del Ejército le rindió honores correspondientes a los de un General de División, un hecho inédito para un civil. ${ }^{3} \mathrm{Al}$ momento de referirse a su prolífica obra los comentarios laudatorios no se hicieron esperar. Miguel Cruchaga Tocornal, a nombre de la Academia Chilena de la Historia, fundada en 1933 y de la cual el fallecido historiador fue miembro honorario, afirmaba que el nombre de Gonzalo Bulnes “no podrá olvidarse porque encarna como pocos el amor a nuestras glorias nacionales y a las sabias enseñanzas de nuestro pasado". Para el periódico oficial del país, su obra cúlmine, Guerra del Pacífico, era "un monumento levantado al patriotismo chileno, al vigor de sus hombres, al genio de sus estadistas y al valor de sus militares". Aunque su obra "no fue escrita para halagar el sentimiento nacional", afirmaba que su lectura había incidido en exaltar "el orgullo del pueblo", pues la investigación y narración expuestas en sus páginas daban cuenta de una verdadera "epopeya chilena".

Estos no fueron comentarios aislados. En uno de los discursos pronunciados en sus exequias, el Ministro del Interior, Luis Cabrera Poblete, perfiló la trayectoria del historiador que había alcanzado el punto cúlmine de su trayectoria con la publicación de Guerra del Pacifico, verdaderas "páginas maestras, por serenas, verídicas y luminosas". "Historia que nadie ha escrito como él, y que si alguien lo escribiera mejor en el futuro, de fijo no superará ni la claridad admirable del relato ni la augusta imparcialidad de los juicios en él expresados", añadía. Por tamaño aporte al conocimiento del pasado nacional, Bulnes había alcanzado a el sitial de ser quizá "el primero de los historiadores de Chile", pues "quien

2 Pantoja Cerda, 1936.

3 ElMercurio, Santiago, 20 de agosto de 1936.

4 Cruchaga Tocornal, 1936.

5 La Nación, Santiago, 18 de agosto de 1936. 
escribe una obra como su Guerra del Pacifico, levanta con sus propias manos el monumento que perpetuará su nombre". 6

¿Cómo un historiador llegó a tener tanta relevancia pública? La respuesta debe situarse en el vínculo profundo entre la producción historiográfica y la idea de nación, un vínculo que Gonzalo Bulnes encarnó de manera privilegiada. Su labor develando el pasado nacional a través de la narración y análisis de los momentos decisivos del siglo XIX, que en su perspectiva eran sin duda las guerras internacionales que había peleado - y ganado - el naciente Estado de Chile, lo posicionaron en la esfera pública como el historiador oficial de las glorias nacionales. En este sentido, la producción historiográfica de Gonzalo Bulnes contribuyó a reforzar la identidad nacional enfatizando la relevancia del factor bélico en la definición de la nación y promover el orgullo patrio al presentar una imagen de Chile como la de una potencia a nivel subcontinental construida durante la centuria decimonónica. Tales imaginarios gozaron de una amplia receptividad social a fines del siglo XIX e inicios del siglo XX, colocando a Bulnes en un sitial privilegiado como productor autorizado de discursos sobre lo nacional en clave histórica.

El vínculo entre historiografía y nacionalismo en el mundo contemporáneo resulta clave. De acuerdo con lo que sugiere Paul Lawrence, la escritura de la historia fue central para el nacionalismo cultural, en tanto proporcionaba "un sentido autoritativo de continuidad con el pasado" y "un sentido de identidad de grupo en el presente". Este vínculo de continuidad temporal resultaría ser especialmente importante para comunidades en proceso de modernización y transformación social. ${ }^{7}$ Esa dimensión temporal de la nación, como comunidad de pasado y destino, es fundamental para entender por qué la relación entre historia y nacionalismo no es accesoria, sino esencial. Como afirma Anthony D. Smith, el nacionalismo es "profundamente historicista en su carácter", en tanto concibe al mundo como el resultado de la interacción de diferentes comunidades, las cuales poseen una historia y carácter únicos, cada una como resultado de orígenes y desarrollos específicos. De ahí que no resulte extraño encontrar entre sus cultores más significativos a los historiadores. ${ }^{8}$ Como lo plantea con ironía Hobsbawm, "los

6 El Mercurio, Santiago, 19 de agosto de 1936.

7 Lawrence, 2013: 725.

8 Smith, 1992: 58. 
\begin{tabular}{r|r} 
G. Cid & 26/27: pp.209-240 \\
Cuadernos de Historia. Serie economía y sociedad &
\end{tabular}

historiadores somos al nacionalismo lo que los cultivadores de amapola en Pakistán son a los adictos a la heroina: les suministramos la materia prima esencial para el mercado". Y agrega: "una nación sin pasado es algo contradictorio. Lo que hace a una nación es el pasado, lo que justifica que una nación esté en contra de otras es el pasado y los historiadores son las personas que lo producen".?

De este modo, los historiadores desempeñan un rol clave en la formulación histórica de discursos nacionalistas en tanto proporcionan relatos autorizados del pasado. Como han argumentado François Hartog y Jacques Revel, dada la importancia colectiva de las visiones del pasado, el discurso histórico con frecuencia es objeto de usos sociales, políticos e ideológicos que apelan a éste como un insumo indispensable para construir la legitimidad de sus demandas. Así, el pasado puede ser utilizado para la elaboración de relatos de orígenes de la nación, como un relato de ruptura - especialmente en casos revolucionarios -, como un relato apologético para exculpar los momentos difíciles del pasado, entre otros. ${ }^{10}$ Dentro de estos usos públicos del pasado, el nacionalismo como ideología tiene algunos rasgos que lo diferencian. Con frecuencia la utilización nacionalista del pasado se distingue por poseer lo que Matthew Levinger y Paula Franklin llaman una "estructura triádica". Esta se caracteriza por la elaboración de una supuesta "edad de oro" de la nación, donde su grandeza se habría forjado gracias a la existencia de una comunidad unificada y armoniosa. Como un espejo en negativo, a esta era de grandeza nacional sucedería un "presente degradado", donde la comunidad nacional entraría en una fase de decadencia ante la pérdida de aquellas virtudes que habrían posibilitado la grandeza patria. Por último, en términos de movilización social la retórica nacionalista insistiría en que para avanzar hacia un futuro utópico, resulta fundamental reconstituir el ethos nacional mediante la restauración de los valores identificados como propios de la "edad dorada". ${ }^{11}$

Como veremos, este patrón de usos del pasado fue clave para entender el impacto de la obra de Gonzalo Bulnes en el imaginario nacionalista chileno de inicios del siglo XX. Este artículo aborda el vínculo entre historiografía, nacionalismo y los usos públicos del pasado a través del estudio de su obra cúlmine, Guerra del Pacífico (19111919). La obra del prolífico autor se propuso fijar el relato chileno sobre la contienda

9 Hobsbawm, 1992: 3.

10 Hartog \& Revel, 2001: 14.

11 Levinger \& Franklin, 2001. 
en un escenario de controversias diplomáticas sobre las consecuencias territoriales del conflicto de 1879. En efecto, aunque la Guerra del Pacífico culminó en 1884, las consecuencias diplomáticas del enfrentamiento entre Chile contra la alianza PerúBoliviana solo se zanjaron en el siglo XX. En 1904 se efectuaron los Tratados de Paz con Bolivia, mientras que los diferendos limítrofes con Perú respecto a la soberanía de los territorios de Tacna y Arica culminaron recién en 1929, con el Tratado de Lima. El libro en tres volúmenes de Gonzalo Bulnes, un erudito historiador de los conflictos bélicos del siglo XIX, fue publicada justamente en este contexto de incertidumbre en las relaciones exteriores, donde se propuso revindicar explícitamente la causa chilena frente a la opinión pública internacional. Pero también la publicación de Guerra del Pacífico coincidió con un momento histórico de clara hegemonía del discurso nacionalista, que encontró en el conflicto de 1879 una cantera prolífica de héroes, batallas, imaginerías y narrativas patrióticas, constituyéndose la obra de Bulnes en un texto de referencia y, pese a su carácter monumental, bastante popular en términos editoriales. En síntesis, el artículo se propone reconstruir la función diplomática e identitaria que asumió la escritura histórica en ese período crucial, enfocándose en la producción historiográfica y la recepción social de la obra. Este es un aspecto novedoso que conviene destacar. En efecto, aunque Guerra del Pacifico ha sido examinada por la historiografía chilena desde su trama documental y el argumento que la sostiene - como lo ha hecho Patricio Ibarra ${ }^{12}$ - poco se ha hablado tanto del contexto de recepción de la obra como de sus usos sociales y diplomáticos de las que fue objeto. Ese es el eje de este artículo.

En lo que sigue, examinaremos la producción historiográfica de Gonzalo Bulnes para situar su trilogía sobre el conflicto de 1879 dentro del corpus de su autor. En segundo término, analizaremos el argumento de Guerra del Pacifico para evidenciar las razones por las cuales dicho libro se constituyó en una referencia clave para las corrientes nacionalistas chilenas de inicios del siglo XX. En tercer lugar, abordaremos el contexto de producción y difusión de esta obra en la esfera pública chilena, prestando atención a los usos patrióticos que se hicieron de ella y los comentarios realizados en torno a sus contenidos. Finalmente, indagaremos en los usos políticos que algunos sectores

12 Ibarra, 2018. 
vinculados al mundo castrense hicieron de la obra de Gonzalo Bulnes y en los usos diplomáticos de las que fue objeto Guerra del Pacífico de cara a la resolución de los diferendos limítrofes por las regiones de Tacna y Arica.

\section{Gonzalo Bulnes: historiografía, guerra y nación}

Gonzalo Bulnes nació en Santiago en 1851, justo el año en que su padre, Manuel Bulnes, abandonaba la presidencia de la república después de una década en el gobierno. Su vida se desarrolló en el seno de una familia de la clase dirigente chilena y marcada por una fuerte impronta militar. Su padre había desarrollado las campañas militares de la independencia y fue el general en jefe de las fuerzas chilenas que derrotaron en la batalla de Yungay (20 de enero de 1839) a las fuerzas de la Confederación Perú-Boliviana. Sus relaciones familiares lo situaron en el centro de la historia política del país en el siglo XIX. Al decir de un biógrafo, su persona "presenció y oyó todas las intimidades de nuestra vida civil y guerrera. Cada uno de sus recuerdos era un pedazo de nuestra historia". ${ }^{13}$

Sus estudios los realizó en el Instituto Nacional, donde recibió la influencia del historiador Diego Barros Arana, quien fungió como rector del establecimiento entre 1863 y 1872. En la década de 1870 Bulnes viajó a estudiar a Europa, especialmente a Francia, en donde tomó cursos con Ernest Renán. De vuelta al país, comenzó a publicar algunos artículos históricos en las páginas de las revistas culturales de la capital, enfocándose en el período de la Independencia y en la Guerra contra la Confederación Perú-Boliviana. Estas dimensiones formativas fueron claves en su trabajo posterior. En primer lugar, por asumir abiertamente una perspectiva positivista de la historia, centrada en la investigación documental en fuentes inéditas para sostener el relato histórico en el entendido de que por esa vía podría asegurarse la "verdad" de los hechos narrados. En este sentido, la impronta de Diego Barros Arana, la figura historiográfica descollante en el medio chileno de la segunda mitad del siglo XIX, cuya monumental Historia General de Chile (1884-1902) publicada en 16 volúmenes fue el

13 Marín, 1940: 18-19. 
punto cúlmine de la literatura histórica en el país, ${ }^{14}$ fue central para el novel escritor. Bulnes se reconocía su discípulo, admirando su rigurosidad, el acopio de fuentes que lucía en sus libros y, especialmente, la imparcialidad de su juicio. "Desde que tomaba la pluma en la mano se revestía de un sacerdocio de justicia y de verdad. Ni aún en sus escritos de polémica incurrió en una frase destemplada, ni en apreciaciones notoriamente injustas", afirmaba. ${ }^{15}$ Junto a esta perspectiva, destaca su interés primordial en los sucesos bélicos del país, en aquellas guerras que forjaron la construcción de la nación en el siglo XIX. Dicho énfasis lo hicieron ser un historiador cercano al nacionalismo, afirma Juan Luis Ossa. ${ }^{16}$ Sin embargo, como argumenta Cristián Gazmuri, fue el énfasis en el acopio documental, en la estructura del relato y la imparcialidad de sus juicios los que lograron que sus textos, sin bien centrados en hitos nacionalistas, no se convirtieran en "manifiestos patrioteros o líricos". Por el contrario, agrega, "Bulnes está muy cerca de lo que podría considerarse un historiador profesional' ${ }^{17}$

Estas características relucieron en su primer libro de historia, publicado a fines de 1878 . Este versaba sobre la Guerra contra la Confederación Perú-Boliviana (1836-1839), el conflicto que había posicionado a su padre como héroe nacional y le había abierto el camino hacia la presidencia de la república. En su Historia de la campaña del Perú en 1838 Bulnes plasmó lo que serían las características más evidentes de su trabajo como escritor. Por un lado, un cuidado por el uso de fuentes oficiales y repositorios documentales inéditos, como epistolarios y diarios de campaña, uso de documentos que le permitirían neutralizar ante el auditorio las sospechas de parcialidad en su interpretación de la campaña. Pero también, el uso de la historia como estímulo para fomentar el patriotismo en el auditorio, según confesaba en el prólogo:

Mi objeto estará cumplido si puedo despertar en el corazón del pueblo el interés por esos sucesos que constituyen la más pura de las glorias nacionales, y si consigo que una parte del país vuelva los ojos a ese pasado, en que se pusieron de relieve las más grandes virtudes de otra época, la firmeza de propósitos, la energía de los caracteres y la pureza del patriotismo ${ }^{18}$

14 Yaeger, 1981.

15 Bulnes, 1907.

16 Ossa, 2013: 186.

17 Gazmuri, 2006, I: 159-160

18 Bulnes, 1878: VII-VIII. En adelante, salvo en los títulos de las obras citadas, la ortografía ha sido actualizada. Para un análisis de esta obra, véase Ossa, 2005. 
El esquema narrativo desde el cual fue concebido el libro estaba orientado justamente a mover este tipo de fibras. En efecto, la Historia de la campaña del Perú en 1838 se estructuraba desde una perspectiva del desarrollo de la campaña con un registro épico y con altas dosis de dramatismo, donde las tropas chilenas lograban sobreponerse sistemáticamente a las adversidades de la guerra, como traiciones, inferioridad numérica, enfermedades, inclemencias meteorológicas, las duras condiciones topográficas hasta alcanzar la victoria definitiva en los campos de Yungay. La batalla del 20 de enero de 1839 fue pensada como el clímax narrativo del libro, donde se condensaron las virtudes guerreras de la nación en un conflicto que "vino a ser el complemento de la guerra de la independencia" y que aseguró para Chile "el puesto que le correspondia en el concierto americano". ${ }^{19}$

Al ser publicado, el libro fue alabado por el prolífico historiador Benjamín Vicuña Mackenna, justamente por poseer esas cualidades narrativas. El relato era cautivante, pues la prosa expresaba un “ánimo apasionado y juvenil' presentes en páginas narradas "con acentuación y brío", especialmente en las que describían la batalla de Yungay, cuando el libro alcanzaba "las proporciones de una obra de primera nota literaria como drama histórico militar". ${ }^{20}$ Por esas ironías de la historia, un par de meses después de la publicación de su primera obra histórica, el libro de Bulnes alcanzaría una contemporaneidad insospechada. En efecto, a inicios de 1879 estalló la crisis diplomática que en abril desembocaría en el inicio de hostilidades entre Chile contra la coalición Perú-Boliviana. El inicio de la Guerra del Pacífico y la actualización simbólica del conflicto previo historiado por Bulnes incidió en que su obra alcanzase una importancia inusitada para una obra histórica en la época, especialmente porque el auditorio creyó ver una continuidad clara entre la guerra de 1836-1839 con el enfrentamiento de 1879, siendo utilizado el libro de Bulnes para difundir entre la población la confianza de una nueva victoria chilena ante sus vecinos del norte. ${ }^{21}$ Así, porciones del texto del historiador fueron profusamente difundidas en la prensa de la época, especialmente para establecer

19 Bulnes, 1878: 442.

20 Vicuña Mackenna, 1936: 24-35. El artículo fue publicado originalmente a fines de 1878.

21 Sobre los usos patrióticos del imaginario de la Guerra contra la Confederación en el contexto de la Guerra del Pacífico, véase Cid, 2011: 161-186. 
el relato canónico de la victoria chilena en Yungay, narración que inspiraría el patriotismo de la población. ${ }^{22}$

Tras la victoria en la guerra, Gonzalo Bulnes pasó a formar parte de la burocracia chilena que el Estado desplegó para nacionalizar los nuevos territorios incorporados a la soberanía, como lo evidencia su nombramiento como Intendente de Tarapacá, desplegando una intensa actividad. ${ }^{23}$ Él mismo recordó que en desempeño de ese cargo promulgó el bando que incorporaba la región de Tarapacá a la soberanía chilena. Allí también recorrió el teatro de desarrollo del conflicto, cuestión que incidiría posteriormente en su reflexión histórica: "Entonces recorrí los campos de batalla y fui a Tacna y también recorrí los campos acompañado de los jefes que se habian batido abi. De modo que me formé un concepto objetivo de esas acciones, que me ha servido después". ${ }^{24}$

Durante la década de 1880 el período de la Independencia y las relaciones con Perú formaron parte de su agenda investigativa, desarrollada en paralelo a su actividad parlamentaria. En 1887 dio a la luz su Historia de la Expedición Libertadora del Perú (18171822), obra que dedicó a la memoria del difunto historiador Benjamín Vicuña Mackenna. En ella, y con gran acopio documental de material inédito, se propuso reconstruir los esfuerzos desplegados por San Martín y O’Higgins por la liberación del Perú. Esta obra, afirmaba Bulnes, debía ser entendida como parte de un panorama más ambicioso que en conjunto con su Historia de la campaña del Perú en 1838 trazaría “"un cuadro histórico de nuestras antiguas relaciones con el Perü; de lo que hemos hecho por ély por nosotros, por su independencia y por nuestro honor? ${ }^{25}$ El proyecto fue aumentado una década después con Últimas campañas de la independencia del Perú (1822-1826), libro que debía comprenderse como la continuación cronológica del anterior. Con sus libros, afirmaba Bulnes, "quedará completa la bistoria de nuestras relaciones con el Perú hasta 1840, y solo faltará escribir la de la campaña de 1879". ${ }^{26}$

22 Algunos ejemplos de la utilización patriótica de la obra de Gonzalo Bulnes, en especial de su narración de la batalla de Yungay, se encuentran en Las Novedades, Santiago, 20 de enero de 1879; El Atacama, Copiapó, 20 de enero de 1880; La Libertad, Talca, 20 de enero de 1880; El Constituyente, Copiapó, 20 de enero de 1880; Los Tiempos, Santiago, 20 de enero de 1881; El Independiente, Santiago, 20 de enero de 1881; y La Patria, Valparaíso, 20 de enero de 1881.

23 Donoso, 2012.

24 Donoso, 1947: 271.

25 Bulnes, 1887: 7.

26 Bulnes, 1897: VII. 
Antes de emprender la realización de la obra que culminaría su ambicioso proyecto historiográfico, Bulnes continúo ejerciendo el oficio de escritor para legitimar la posición chilena en sus relaciones vecinales. Aquí Bulnes se insertó en la tradición de la segunda mitad del siglo XIX chileno en la cual los historiadores se volvieron de facto en "diplomáticos", alineándose con los gobiernos para suministrar pruebas documentales y sustentar las posiciones nacionales en los diferendos limítrofes con las naciones vecinas. ${ }^{27} \mathrm{~A}$ fines de la tensa década de 1890 su mirada estuvo puesta en las relaciones con Argentina, país con el cual Chile estuvo cercano a la guerra por las controversias respecto a la demarcación de sus respectivas fronteras. ${ }^{28}$ En dicho escenario, Bulnes reivindicó el papel del historiador, que con "documentos de verdadera autoridad" podía defender la causa nacional ante la opinión pública e instar a una solución pacífica de las controversias. Así, definió su libro Chile y la Argentina. Un debate de 55 años! como "una obra de paz; obra de aproximación; una palabra amistosa y sincera al pueblo argentino, que vale más que los pequeños Maquiavelos que hacen consistir el patriotismo en el enredo". ${ }^{29}$ Afortunadamente, las tensas relaciones entre ambos países tuvieron un cauce de acuerdo con los Pactos de Mayo de 1902, deliberaciones en las cuales Bulnes tomó parte como miembro de la comisión chilena.

\section{Guerra del Pacífico (1911-1919): el triunfo de "una raza" y "una historia"}

Tras un par de décadas de investigación, en septiembre de 1911 Gonzalo Bulnes daba a la luz por la Imprenta Universo el primer volumen de lo que constituiría su obra magna: Guerra del Pacifico. En un esquema narrativo que analizaba el desarrollo de la guerra a través sus campañas militares, Bulnes dedicó su primer volumen a examinar los prolegómenos diplomáticos del conflicto, la ocupación chilena de Antofagasta a inicios de 1879, la campaña naval hasta el combate de Angamos y la culminación del primer año de la guerra con la campaña de Tarapacá, que supuso la anexión de esa región al dominio chileno. A mediados de 1914 aparecía la segunda parte de la trilogía,

27 Woll, 1982: 105-126.

28 Brahm, 2002.

29 Bulnes, 1898: 8-9. 
que abarcaría probablemente los sucesos más importantes de la guerra para el auditorio chileno. En éste abordaba la victoria sobre la coalición en la batalla de Tacna (mayo de 1880), que significó que Bolivia abandonara el conflicto, y la posterior la ocupación de Arica (junio de 1880). El momento cúlmine de la guerra, con el que selló el segundo volumen fue el desenlace de la campaña de Lima, que tras las batallas de San Juan, Chorrillos y Miraflores permitieron la ocupación de la capital peruana por las fuerzas chilenas. En 1919 se publicaría el volumen final de Guerra del Pacifico, que abarcó el período de la ocupación del Perú, la campaña de la sierra y los dilemas diplomáticos de la gestión de la paz con la alianza peruano-boliviana, dedicándole especial atención a las tratativas que culminaron en el Tratado de Ancón.

Como era habitual en sus trabajos, Bulnes explicitó sus fuentes como un mecanismo de validación de su investigación que le permitiría asegurar la imparcialidad de su relato y justificó el prurito de erudición expresado en las más de dos mil páginas de Guerra del Pacifico. En ese registro, el historiador confesó que debió sacrificar el dinamismo del relato por la rigurosidad de la pesquisa, confiriéndole a la obra un carácter monumental. Esto debía ser así, agregaba, porque "la Guerra del Pacifico se encuentra en el periodo documental, en que es preciso establecer los hechos con verdad, porque aún no lo están". ${ }^{30} \mathrm{Y}$ en esa etapa, el despliegue de las cualidades propias de su oficio que había evidenciado en su trayectoria como escritor debían relucir. Correspondencia diplomática inédita, memorias militares, diarios de campaña, sesiones parlamentarias secretas, entre otros, formaron parte de la amplia panoplia de recursos documentales compulsados por Bulnes para asegurar la verosimilitud de su propuesta.

La idea de imparcialidad histórica era clave para Bulnes, especialmente en un tema tan controversial como la guerra. De ahí que en el prólogo de su trilogía asemejara el trabajo del historiador con el de un fotógrafo, por la pretensión de verdad que subyacía a la labor de retratar "los hechos y los hombres tales como fueron". Solo así, con sus luces y sombras, el pasado podía albergar la capacidad de interpelar y aleccionar al presente. Y en medio del escenario diplomático en el que se encontraba Chile, ese repositorio de enseñanzas era más valioso que nunca. La pretensión de Bulnes era que al plasmar los hechos desde esta perspectiva de imparcialidad autoimpuesta, si "el país vuelve a

30 Bulnes, 1911-1919, I: VIII. 
encontrarse en una situación análoga pueda sacar de estos sucesos las lecciones que se desprenden de ellos". ${ }^{31}$

Pese a las declaraciones de que la amplitud de fuentes compulsadas y la erudición que sostenía el argumento garantizaría la imparcialidad de su interpretación, lo cierto es que el aura nacionalista que rodeaba a la victoria chilena en la guerra de 1879 y las sensibilidades patrióticas contemporáneas del momento de producción de la obra aspecto que abordaremos en detalle en la siguiente sección - hicieron que la dimensión cívica del trabajo histórico fuera evidente. En el prólogo del primer volumen, Bulnes declaró sin ambages: "Este libro me ha enseñado que el amor de la Patria es un sentimiento que se debe cultivar hasta por egoísmo", agregando que su esperanza era "que mi país aprovechara este trabajo ya que recordarle sus glorias es hacerle un llamamiento a sus deberes". Y se preguntaba: “ ¿Será ilusión pensar que el que lo lea se sentirá más obligado que antes a mantener el prestigio de la República en el rango en que lo colocó la generación de 1879?’.32 La idea de que la historia permitiría incentivar las virtudes cívicas de la población al confrontarlas con la grandeza del pasado nacional fue una de las ideas fuerza que orientó la producción de la trilogía de Bulnes, y que se empeñó en reivindicar en la introducción al segundo volumen. Allí reconoció que su deseo era que el libro se convirtiera "en un espejo en que las generaciones venideras contemplen la magnitud de sus deberes, o un árbol en que esas mismas generaciones busquen la sombra refrescante de los grandes recuerdos y de las resoluciones alentadas en los momentos de tribulación que han de venir". ${ }^{33}$

En términos interpretativos, el libro de Bulnes se caracterizó por poner de relieve la estabilidad política e institucional del país, la amplitud de la movilización popular en la causa bélica y la solidez de la conducción civil en la guerra como factores cruciales que permitían entender la victoria chilena. Como ha argumentado Patricio Ibarra, en "la supremacia del estamento civil por sobre el militar en la dirección de la guerra", especialmente cuando se le confrontaba al caudillismo y militarismo de los antagonistas, Bulnes vio una de las claves de lectura para el triunfo en la conflagración, el triunfo de la "nación en armas". ${ }^{34}$ Esta interpretación entroncaba con una perspectiva histórica mayor, que

31 Bulnes, 1911-1919, I: VII.

32 Bulnes, 1911-1919, I: IX.

33 Bulnes, 1911-1919, II: VI.

34 Ibarra, 2018: 289-294. 
concebía al siglo XIX como la realización la república, que de manera ascendente ratificaría la autopercepción de las elites chilenas de haber forjado un proyecto nacional exitoso en el concierto hispanoamericano. Así, como sugiere Simon Collier, en el fondo del argumento de la obra de Gonzalo Bulnes se plasma "una versión chilena de la interpretación whig de la bistoria", donde el pasado es una cadena ascendente de desarrollo institucional, político y civil que culmina con el triunfo en el conflicto de $1879 .{ }^{35}$

El entusiasta despliegue de energías de la sociedad civil chilena para sostener el esfuerzo de guerra y engrosar los cuadros militares fue una de las claves de la victoria. "La república se convirtió en un taller en que nadie escatimaba el sacrificio", afirmaba Bulnes. ${ }^{36}$ Incluso en medio de la improvisación que supuso un conflicto imprevisto, las deficiencias se "suplian a fuerza de patriotismo", sentimiento que satisfizo todas las demandas de la guerra: pertrechos, municiones, medicinas, alimentación, vestimenta, etc. La imagen de la nación perfectamente cohesionada detrás del gobierno, sin fisuras sociales, regionales, raciales o políticas permitía entender la superioridad chilena ante sus rivales. Porque en 1879 "las clases sociales, sin distinción, respondieron unánimemente al llamado del gobierno, y si uno caía en la brecha, veinte corrian a llenar el claro". ${ }^{37}$

El exitoso desarrollo de las campañas militares potenció estas actitudes cívicas, demostrando como se fue ensanchando "más y más en el país la ola del sacrificio". La conducción de esa energía patriótica recayó en las dirigencias político-civiles del país, cuya figura más destacada fue la de Rafael Sotomayor, el Ministro en campaña, muerto en plena actividad. Él encarnó a la figura del "abnegado funcionario" devenido en epítome del burócrata patriota, modesto y desinteresado. "Cuando la posteridad recuerde lo que hizo Chile en 1879 y 1880 tendrá que decir que el obrero más poderoso de su grandeza fue ese ciudadano que se excedia en las horas opacas y se ocultaba en las del triunfo", concluía Bulnes. ${ }^{38}$

En el despliegue de estas virtudes cívicas, ampliamente diseminadas en la población y encarnadas en un puñado de burócratas destacados, debía hallarse una de las claves de la victoria chilena. Porque esta no podría explicarse históricamente por un afán expansionista o militarista del país. Contrariamente a la imagen internacional que se

35 Collier, 1977: 668.

36 Bulnes, 1911-1919, I: 464.

37 Bulnes, 1911-1919, II: 721-725.

38 Bulnes, 1911-1919, I: 465. 
instaló de Chile en la época de la guerra, de ser la "Prusia americana", ${ }^{99}$ Bulnes reivindicó la idea de que el país fue empujado hacia un conflicto no deseado por el tratado secreto peruano-boliviano de 1873. En ese sentido, acotaba el historiador, "la guerra fue por parte de Chile defensiva de su nacionalidad. Hubo un plan para suprimirlo y se propuso desarmar a los conjurados". Si Chile procedió a declarar la guerra y ocupar el Perú, fue sencillamente para poner a aquel país en la imposibilidad de amenazar la existencia nacional nuevamente. Fue así un conflicto para "cerrar la era de la guerra y garantir con su propia seguridad la paz de América". ${ }^{40}$ La prueba de la ausencia de militarismo en Chile previo al conflicto era la pequeñez del ejército nacional. Un ejército diminuto - 2440 hombres -, propio "de un pueblo como el nuestro que se ha desarrollado en la legalidad y en la paz". Sin embargo, pese a su escaso contingente, se caracterizaba por su disciplina, frugalidad en sus costumbres y, sobre todo, sumisión a las autoridades civiles. Era, en síntesis, "una materia prima muy buena, que era preciso moldear". ${ }^{41}$

Una ciudadanía comprometida con el esfuerzo de guerra, una sociedad cohesionada en torno al conflicto, unas dirigencias civiles capaces de organizar las campañas militares y un ejército pequeño, disciplinado y aguerrido eran factores claves que para Gonzalo Bulnes permitían entender cómo Chile logró derrotar a dos adversarios demográficamente muy superiores. Pero esas virtudes obedecían a causas históricas más profundas de acuerdo con el escritor. La principal de ella era la solidez institucional del país a lo largo del siglo XIX, que ni siquiera fue interrumpida por el conflicto de 1879. "Durante la campaña no se alteró en Chile la vida constitucional. El Congreso funcionó como de ordinario. Leyes, algunas de gran entidad, llevan la fecha de esos años y las libertades fundamentales no sufrieron alteración alguna", sentenciaba. ${ }^{42}$ Por eso, el triunfo de Chile en la Guerra del Pacífico coronaría una historia de excepcionalidad continental. Como afirmó Bulnes en una frase clave: "Lo que venció al Perú fue la superioridad de una raza y la superioridad de una historia; el orden contra el desorden; un país sin caudillos contra otro aquejado de ese terrible mal'. ${ }^{43}$ Porque mientras los soldados chilenos se batían por la patria, los peruanos lo hacían por alguno de los múltiples caudillos que se disputaban los despojos de la

39 Rubilar, 2015.

40 Bulnes, 1911-1919, III: 619.

41 Bulnes, 1911-1919, I: 188.

42 Bulnes, 1911-1919, III: 618.

43 Bulnes, 1911-1919, II: 699. 
república derrotada. "Eso es lo que habia vencido: la superioridad de una historia sana y moral sobre otra convulsionada por los intereses personales. No diré que es la única causa de la derrota, pero si que tuvo parte en ella", concluía. ${ }^{44}$

\title{
Un pasado funcional: los usos patrióticos de Guerra del Pacífico
}

Apenas unos días antes de salir a la luz el primer volumen de Guerra del Pacífico, Gonzalo Bulnes cuestionó en un artículo periodístico los dichos del parlamentario Paulino Alfonso, quien en la Cámara de Diputados se opuso a la adquisición de nuevos acorazados para el país. Para el diputado del Partido Liberal Doctrinario, Chile no los necesitaba porque ese poderío era propio de una "potencia" y el país no lo era, ni siquiera a nivel americano. Gonzalo Bulnes criticó duramente este planteamiento, no solamente porque ponía en duda que Chile fuese "una nación fuerte, consciente de su tradición y de sus destinos", sino también porque daba una señal de debilidad ante el Perú en medio de los diferendos limítrofes de ambos países. El argumento ignoraba que aún en épocas de mayores estrecheces económicas, como lo fue el siglo XIX, Chile había logrado posicionarse como una potencia continental a nivel político y militar. Bulnes, que había dedicado su labor como historiador de narrar este proceso, insistía en que como una "nación de primer orden", el país debía asegurar su poderío militar y concluía realizando una apología de la grandeza de Chile:

\begin{abstract}
Somos tres millones de hombres con una gran historia, que es una fuerza moral inmensa. Somos una nacionalidad compacta y unida, con vibraciones y latidos iguales de arriba abajo. Detrás de nuestro Ejército marchan nombres y recuerdos que alientan al sacrificio, fuerza que no tiene ningún otro pueblo en Sud-América. Poseemos una raza inteligente, patriota, y pese a quien le pese, hoy por hoy somos el único país de la América española que puede organizar un ejército de cien mil hombres bajo condiciones de perfecta homogeneidad. ${ }^{45}$
\end{abstract}

Esta afirmación nos permite entender el contexto de recepción de la obra, las sensibilidades movilizadas y el argumento nacionalista que Bulnes buscaba instalar con

44 Bulnes, 1911-1919, II: 699-700.

45 Bulnes, 1911. 
su obra sobre la Guerra del Pacífico. La idea central era que la grandeza que Chile había forjado durante el siglo XIX y que había alcanzado su clímax en el triunfo de 1879 corría el riesgo de diluirse, así como las virtudes cívicas que habían posibilitado la victoria. Reposicionar la historia gloriosa del país, confrontándola a un presente que para sus contemporáneos parecía ser decadente, fue la fibra patriótica que Bulnes tocó a través de su obra, constituyéndose en un texto capital para un nacionalismo cercano a un registro restauracionista, anti-parlamentario y filo-militarista. Ese registro argumental encontró un contexto muy receptivo en diferentes círculos políticos, sociales e intelectuales. En efecto, durante las primeras décadas del siglo XX proliferaron los discursos que afirmaban que el país se encontraba en "crisis" y en “decadencia”, cuyos orígenes se situaban tras la Guerra del Pacífico. Dichos discursos aglutinaban críticas políticas al parlamentarismo, cuestionamientos a la oligarquía dominante, ataques al sistema de partidos, denuncias contra la irrupción de ideologías “disolventes", reclamos por la pérdida de valores nacionales y a la falta de probidad pública, convirtiéndose en un lugar común en la literatura del período. ${ }^{46}$ En paralelo, el discurso nacionalista alcanzó su momento de mayor popularidad y difusión social, constituyéndose en lo que Bernardo Subercaseaux llama "la fuerza cultural dominante de las primeras décadas", en tanto impregnó las sensibilidades estéticas, la producción cultural e intelectual del período y gozó de una amplia difusión social por medio de rituales cívicos y prácticas pedagógicas. ${ }^{47}$

Antes de salir publicado por las prensas de la editorial Universo, el libro de Bulnes gozó de una gran campaña de difusión por los periódicos. La folletinización de su obra - reciclando una estrategia editorial propia del siglo XIX - fue clave para la masificación de su argumento a una escala inédita para un libro de historia. Así, desde fines de agosto de 1911 la obra fue publicada por capítulos en las ediciones de El Mercurio - en sus ediciones de Valparaíso y Santiago - y en Las Últimas Noticias. La misma estrategia de difusión se realizó en 1914 para la publicación por entregas del segundo volumen, y en 1919, en la parte final de la trilogía de quien se consignó como "el historiador más glorioso de Chile". La obra, publicitada como "el libro que todo chileno debe

46 Gazmuri, 2001.

47 Subercaseaux, 2007: 11. Véase también Cid \& San Francisco, 2010. 
conocer", poseía un "interés sensacional", "si se considera que ella constituye el testimonio lapidario de los derechos de Chile", especialmente por su análisis del Tratado de Ancón. Con este volumen, añadía El Mercurio, se "cierra con broche de oro uno de los libros destinados a ser en Chile la fuente imprescindible para cuantos quieran conocer uno de los períodos y hechos gloriosos del país, que más pueden honrar su historia". ${ }^{48}$

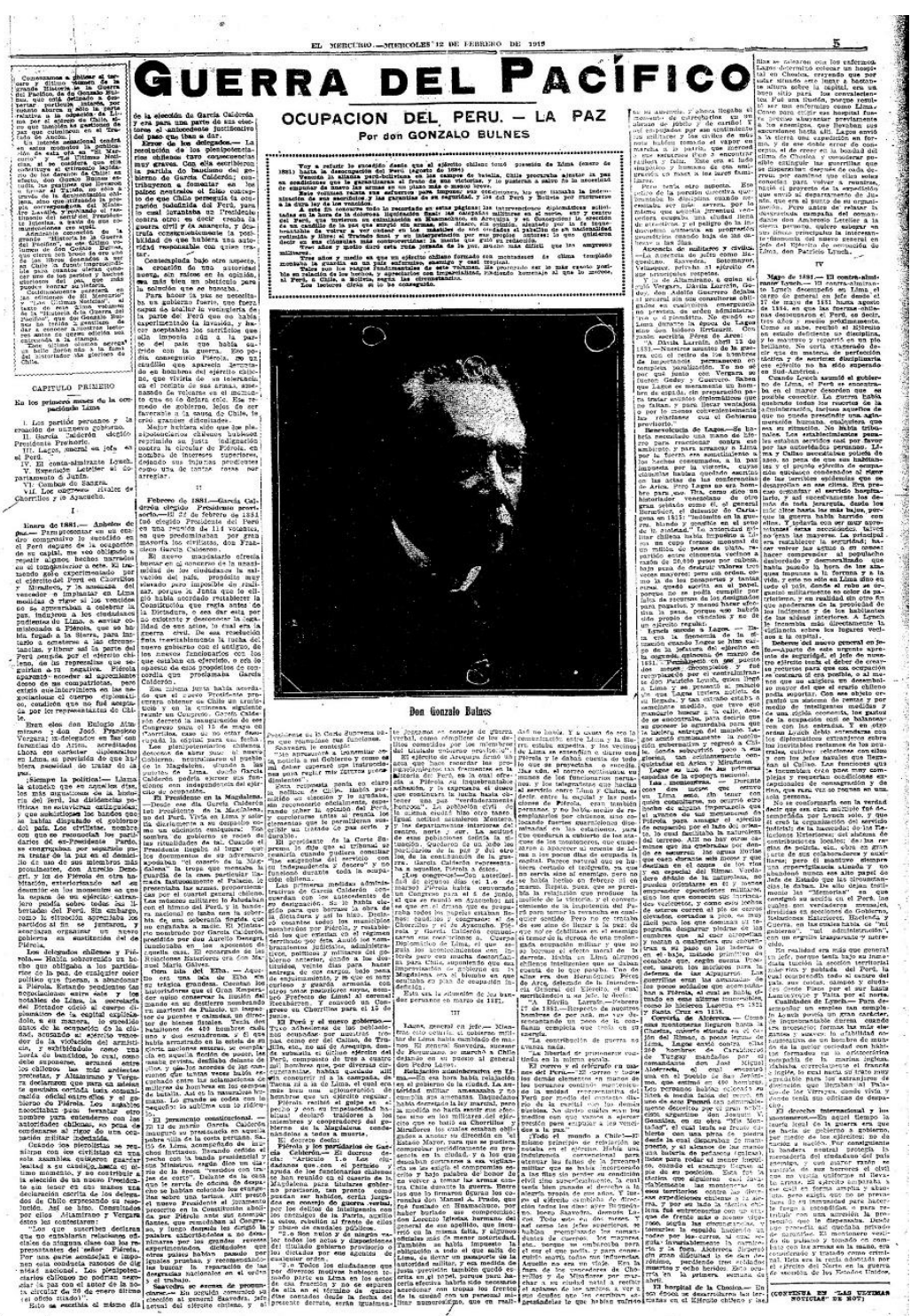

Imagen 1. Publicación por fascículos del tercer volumen de "Guerra del Pacífico", en El Mercurio, Santiago, 12 de febrero de 1919.

48 El Mercurio, Santiago, 12-II-1919. 


\section{\begin{tabular}{l|l} 
Cuadernos de Historia. Serie economía y sociedad & 26/27: pp.209-240
\end{tabular}}

La difusión por la prensa fue clave para acercar la obra de Bulnes al gran público. Como consignó Julio Pérez Canto - director del principal medio del país, El Mercurio - al momento de entregarle una medalla de oro a Gonzalo Bulnes por su obra, esta "pudo penetrar, reproducida en nuestro periódico, hasta en los más humildes hogares, dentro y fuera de la capital, despertando en todas las clases sociales el más legítimo interés". La distinción, agregaba, se le confería no solo porque el libro justificaba a Chile de las acusaciones de los países vecinos y exaltaba a los soldados que hicieron la "epopeya del Pacifico", sino también porque en sus páginas se estimulaba en la población el patriotismo - "la base en que descansan las naciones" -, especialmente en un escenario en que "empiezan a esparcirse en nuestro ambiente doctrinas demoledoras de la patria y de la sociedad". ${ }^{49}$

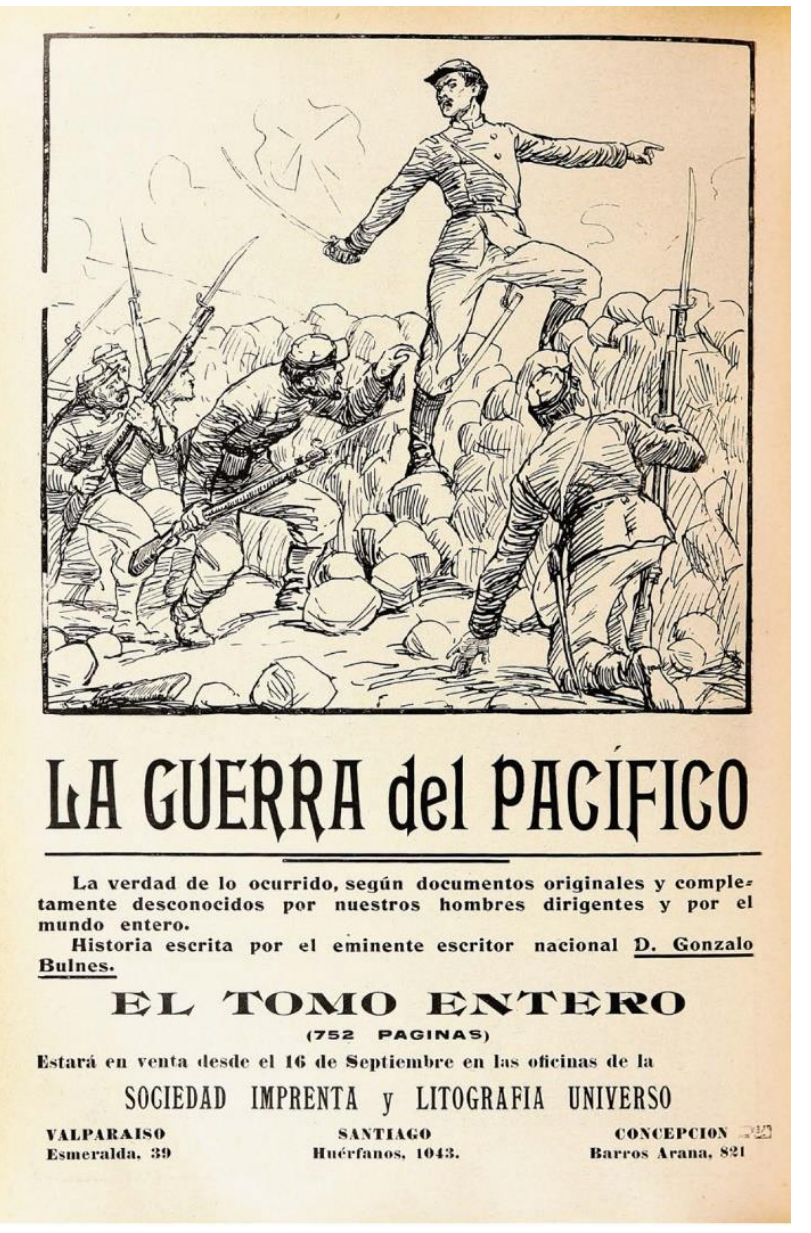

Imagen 2. Afiche promocional de "Guerra del Pacífico", aparecido en Sucesos, Valparaíso, 7 de septiembre de 1911.

49 El Mercurio, Valparaíso, 29-VII-1912. 
De hecho, apenas publicado el libro el Consejo Superior de Letras y Bellas Artes, organismo creado en 1909 para orientar oficialmente el desarrollo cultural del país, sugirió al gobierno la adquisición de los derechos de publicación de Guerra del Pacífico, "en atención a su importancia", para traducirla a diversos idiomas y producir ediciones de bajo costo "a fin de ponerla al alcance del pueblo". ${ }^{0}$ Y aunque la medida no prosperó, sí hubo instancias oficiales que ayudaron a distribuir la obra a gran escala. En las discusiones del presupuesto de 1912, por ejemplo, los parlamentarios acordaron incluir monto de $\$ 3.600$ para adquirir ejemplares del primer volumen para nutrir las bibliotecas militares del país. ${ }^{51}$

Esa forma de acercar la historia de la guerra al gran público le permitió al escritor no solo aumentar su popularidad, sino también ser utilizado por sectores que vieron en su texto un material clave para fomentar la cultura cívica en la población. A fines de 1914 Tancredo Pinochet, un destacado intelectual y educacionista afín al nacionalismo, reconoció que en la campaña de fomento del sentimiento patriótico desplegado al interior de la Escuela de Artes y Oficios de la capital, el uso de la obra de Bulnes fue clave para "encender el espíritu cívico". "Se les leyó a todos, comentada, la segunda parte de la Historia de la Guerra del Pacifico de don Gonzalo Bulnes, a medida que se iba publicando en la prensa de Santiago", indicó, con el fin de "despertar en ellos la iniciativa, el amor al esfuerzo, la sinceridad, la perseverancia, todas las virtudes cardinales que hacen los grandes caracteres". ${ }^{52}$

El mismo autor fue invitado a impartir conferencias sobre el tema. Pese a la exhaustividad de su investigación, la publicación del primer volumen de la Guerra del Pacífico constituyó un fenómeno editorial - pese a sus más de 700 páginas, a un año de su publicación éste había alcanzado la tercera edición - e instaló a Bulnes como una importante figura mediática. Así, meses después de la publicación del primer tomo, la Biblioteca Nacional organizó una conferencia alusiva al aniversario del combate naval de Iquique (21 de mayo de 1879), donde Bulnes fungió como el orador principal. La asistencia fue masiva, en un momento en el que además las sensibilidades nacionalistas

50 El Comercio, Lima, 26 de setiembre de 1911.

51 Chile, Cámara de Senadores, sesión de 15 de noviembre de 1911: 532.

52 Pinochet Le Brun, 1914. 
estaban a flor de piel y en el cual el culto a Arturo Prat - el héroe chileno más popular del conflicto - comenzaba a gozar de una renovada importancia en la esfera pública. ${ }^{53}$ Las revistas culturales y magazinescas contribuyeron a discutir el contenido del libro y posicionar a la figura del historiador como uno de los intelectuales más relevantes del país. Desde las páginas de Selecta, el escritor Miguel Luis Rocuant, en su comentario a la obra de Bulnes señaló que se trataba de un libro a medio camino entre la crónica "fría y descarnada" de Diego Barros Arana y la visión "lírica y encomiástica" típica de Benjamín Vicuña Mackenna, quienes habían historiado el conflicto anteriormente. La nueva publicación, que se anunciaba como la interpretación definitiva de la guerra, dada la distancia crítica que le permitía el tiempo transcurrido y el enorme acopio documental que respaldaba el texto de Bulnes, no podía llegar de manera más oportuna para el país. El escritor declaraba de manera encomiástica:

En los momentos actuales en que, por el natural olvido de las cosas, la opinión pública no estaría lejos de aceptar transacciones indecorosas para terminar con el griterío de los adversarios irreconciliables, esta obra de patriota y de artista ha venido a vigorizarnos, mostrándonos en las glorias del pasado, los deberes del porvenir. Modificar el sentimiento público, señalándole el verdadero camino cuando empezaba a desviarse, es obra de verdad, noble y hermosa cual la célebre de los rapsodos griegos que, enalteciendo glorias olvidadas, desparramaban sus cantos en el pueblo como fecundas semillas de heroísmos. ${ }^{54}$

En otra entrevista, a propósito de la publicación del segundo volumen de Guerra del Pacífico, el escritor Juan Manuel Rodríguez intentó retratar un perfil más íntimo de quien, por sus lazos familiares, encarnaba un legado heroico para el país y a esas alturas se constituía en una figura venerable para la opinión pública nacional. Su libro sobre el conflicto de 1879 lo había catapultado a ese sitial. Rodeado de papeles inéditos, el historiador "nos ha vindicado ante los pueblos americanos, destruyendo las leyendas forjadas por nuestros enemigos", afirmaba el periodista. El acopio de múltiples documentos más la frialdad imparcial de su análisis había logrado perfilar un cuadro verídico de la época y con ello " ha quedado en pie el orgullo de nuestra nacionalidad, la cohesión de la raza y ha quedado demostrado en forma innegable de lo que es capaz. un pueblo que confía en la seriedad de sus hombres

53 El Diario Ilustrado, Santiago, 20 de mayo de 1912; El Mercurio, Santiago, 22 de mayo de 1912. Sobre la renovación del culto a Arturo Prat en la época, véase Sater, 2005: 101-108.

54 Rocuant, 1911. El artículo también se publicó en la revista parisina Mundial Magazine, en mayo de 1912. 
$y$ de sus instituciones" ${ }^{55}$ Un comentario similar fue realizado por el historiador, al evaluar el impacto de la Guerra del Pacífico en el devenir del país. En palabras de Bulnes, pese a referirse a sucesos pasados, la historia de aquel conflicto encerraba una valiosa lección para el presente:

La guerra del 79, nos decía, ha servido para probar una vez más el empuje de la raza. Es por las consecuencias que ha tenido en la vida social, politica y económica de Chile, el acontecimiento más importante de su bistoria en el uiltimo medio siglo. Es útil que el país conozca esa bistoria porque da la medida de lo que él es capaz. de hacer en un momento supremo en que juega sus destinos. La generación de 1879 no fue excepcional. Lo que realizó entonces se puede repetir, si desgraciadamente la ocasión se volviese a presentar. El recuerdo de esa época es el mejor antídoto contra el pesimismo que es la neurastenia de los pueblos y que hay conveniencia en extirpar. Yo tengo fe en que el Chile de hoy sería, si la necesidad lo obligara a ello, tan grande como el de 1879. La tradición es una obligación que impone deberes lo mismo a la familia que a los pueblos ${ }^{56}$

El reconocimiento no solo fue a nivel mediático. La obra de Gonzalo Bulnes también gozó de los elogios de sus pares, que reseñaron positivamente su trabajo. En las páginas de Anales de la Universidad de Chile el parlamentario, diplomático e historiador Francisco Valdés Vergara - autor de diversos manuales escolares de enseñanza de la historia alabó el libro de Bulnes por la madurez disciplinar que evidenciaba y porque coronaba una larga trayectoria historiográfica. El trabajo merecía el "aplauso del país entero", pues era el primer texto que abordaba la guerra desde una perspectiva de conjunto, porque estaba sólidamente documentado y, sobre todo, pues reflejaba un "espiritu de imparcialidad" en su análisis. Bulnes, afirmaba, "no quiere engañar a su país, sino mostrarle la verdad desnuda para que en ella aprenda a precaverse de futuros peligros y a no dormirse otra vez. en la confianza de que nada le amenaza". Y uno de los aspectos esenciales que revelaba el primer volumen de Guerra del Pacífico era que descartaba la idea de Chile como un país expansionista y reivindicaba la idea de que la nación había sido empujada a un conflicto imprevisto ante un plan orquestado por Perú y Bolivia que perseguía "berir a Chile de muerte y reducirlo a una condición acaso tan miserable como la que tuvo en la época colonial'. ${ }^{57}$

55 Rodríguez, 1914.

56 Rodríguez, 1914.

57 Valdés Vergara, 1911: 457-459. El texto también fue publicado en la Revista Chilena de Historia y Geografía. 
Valdés Vergara no estuvo solo en esta apreciación. La aparición en 1914 del segundo volumen de Guerra del Pacífico concitó las alabanzas del historiador Tomás Guevara. Para quien fuera rector del Liceo José Victorino Lastarria de la capital, la obra resultaba modélica por su magistral y amplio uso de fuentes documentales, constituyéndose así en un libro confirme a "cuanto puede exigirse en el concepto moderno de una historia parcial'. Su solidez no solo era respecto a las fuentes compulsadas. En términos de método, Guevara también sostuvo que el trabajo del historiador había avanzado hacia nuevos aspectos metodológicos del análisis de la guerra, tomando en consideración la dimensión psicológica del conflicto. "En la actualidad, la historia contiene mucha psicología individual y colectiva”, y Bulnes daba cuenta de eso. En síntesis, Guerra del Pacifico debía ser positivamente acogido por la sociedad chilena, pues además de "sus observaciones penetrantes y razonadas críticas, la amenidad de un estilo elevado y siempre fácil por su claridad", su contenido era de innegable actualidad, pues despertaba una alerta hacia la política boliviana que impugnaba los tratados limítrofes que habían confinado al país a la mediterraneidad. ${ }^{58}$

Desde la perspectiva del reconocimiento de sus pares hacia Guerra del Pacifico, el hecho más significativo fue la concesión de una medalla de oro por parte de la Sociedad Chilena de Historia y Geografía. La institución, cuya finalidad era el fomento de los estudios históricos y la profesionalización de la disciplina mediante la organización de conferencias y la edición periódica de una revista con criterios académicos - la Revista Chilena de Historia y Geografía, editada desde 1911 - decidió a fines de 1914 entregar la distinción a Gonzalo Bulnes, tras haber publicado el segundo volumen de su trilogía. La ceremonia, llevada a cabo en la Biblioteca Nacional, contó con la presencia de su director, de los miembros de la Sociedad - de la cual Bulnes era miembro honorario y de los Ministros de Hacienda e Instrucción Pública. ${ }^{59}$ El destacado bibliófilo José Toribio Medina afirmó que el homenaje se le concedía a Bulnes en "reconocimiento a su labor de cerca de treinta años, y cuyo brillo se manifestó desde la primera obra que salió de su pluma, hasta la última con que se ha enriquecido la historia patria". Guerra del Pacífico era no solo la

58 Guevara, 1914.

59 ElMercurio, Santiago, 28 de diciembre de 1914. 
culminación de su carrera, sino también un "recuerdo imperecedero de las glorias de los hijos de Chile y ejemplo alentador y luminoso para los que en el futuro se vean en el caso de imitarlos". ${ }^{0}$ Por su parte, el Ministro de Hacienda, miembro de la Sociedad y también historiador, Alberto Edwards, agregó que si había un estudioso del pasado que merecía esa distinción era Bulnes, "por una obra cuya publicación alcanzó las proporciones de un acontecimiento nacional". "Pocos libros han alcanzado en Chile un éxito semejante al de esta obra del señor Bulnes”, añadía. Y la razón no era difícil de imaginar, pues en ella el país vio "evocadas sus glorias y se estremeció de patriótico orgullo". "Al leerla sentimos todos cobrar nueva vida dentro de nuestros pechos al sentimiento nacional', decía Edwards. El gran mérito de la obra de Bulnes fue haber logrado impactar de ese modo el imaginario nacional sin haber sacrificado ni la erudición ni la imparcialidad en sus juicios. Bulnes, un "historiador imparcial y verídico", había logrado construir con su obra un "verdadero monumento de justicia" que refrendaba la posición chilena en medio de los ataques de los que era objeto en la opinión pública internacional, que acusaban a Chile de ser un país militarista y expansionista. ${ }^{61}$

\section{Usos políticos y diplomáticos de una obra}

El entusiasmo que despertó Guerra del Pacífico poseía otras ramificaciones, especialmente porque desde sus utilizaciones patrióticas la obra de Bulnes pronto serviría para justificar fines políticos. En el cambio de siglo, las fuerzas armadas chilena estaban de lleno en un proceso de profesionalización que había comenzado tras la Guerra del Pacífico, con una marcada impronta prusiana. A inicios del siglo XX la politización del ejército comenzaba a ser evidente. A los reclamos por problemas en los ascensos militares, en la reglamentación de sus retiros y sobre la precariedad de sus sueldos, que eran elementos de malestar en el cuerpo castrense, se sumaron elementos de tipo político. En efecto, el culto a los valores nacionales, la exaltación del autoritarismo y el rechazo a la democracia liberal y parlamentaria fueron factores que

60 Sociedad Chilena de Historia y Geografía, 1915: 7.

61 Sociedad Chilena de Historia y Geografía, 1915: 10-12. 
no tardaron en expresarse en la esfera pública, mediante la proliferación de tendencias golpistas en el seno del Ejército. ${ }^{62}$

Para el mundo castrense, la figura de Gonzalo Bulnes no era lejana. En efecto, en su condición de diplomático gestionó en Alemania importantes avances en el proceso de prusianización del ejército chileno. Esos vínculos se volvieron particularmente importantes en la época del Centenario de la independencia (1910), cuando los mandos militares del ejército comenzaron a formar sus propias formas de sociabilidad, como el Club Militar y, especialmente, la Liga Patriótica Militar que sirvieron de plataformas para hacer notar el malestar del cuerpo castrense con la conducción política de la república. ${ }^{63}$ En ese escenario, la comunidad de ideas vertidas en Guerra del Pacifico - la contraposición de un pasado glorioso forjado gracias al cuerpo castrense frente a un presente decadentista - halló eco en los lectores militares de su obra que creyeron encontrar en el historiador Gonzalo Bulnes un portavoz civil de sus deseos de "regeneración" del país y un líder político para un eventual golpe militar. Tal como rememora el escritor Emilio Rodríguez Mendoza, otro de los civiles involucrados en la intentona, a mediados de 1911 fue contactado por algunos mandos militares - el comandante Barrios, el coronel Quiroga Rogers y el mayor Cañas Irarrázaval - que encontraron en sus escritos una comunión de intereses vinculados a la crítica al parlamentarismo y la necesidad de una reacción nacionalista. Para dotar de legitimidad al movimiento, se requería de una figura civil, y para Rodríguez Mendoza nadie encarnaba esas virtudes como Gonzalo Bulnes, que recientemente había dado a la luz el primer volumen de su trilogía sobre la guerra de 1879. "Yo pensaba que el hombre civil que se necesitaba no podía ser otro que el autor de esa gran historia de la guerra", afirmaba. Así comenzaron los acercamientos entre Bulnes y el mundo castrense. En septiembre de 1911 el historiador fue el único civil invitado a un banquete militar. A fines de año fue el orador principal en los fastuosos funerales del coronel Jorge Barceló Lira. En enero de 1912, a instancias de Rodríguez Mendoza, Gonzalo Bulnes fue contactado con los cabecillas del movimiento militar con quienes sostuvo reuniones en su domicilio. Sin

62 Corvalán Márquez, 2009: 179-186, Quiroga \& Maldonado, 1988: 85-86, Millar, 1972-1973: 33-55.

63 Nunn, 1970: 316-317. 
embargo, después de considerar la situación, el historiador dio un paso al costado y decidió no involucrarse en el movimiento. ${ }^{64}$

Las proyecciones de su trabajo no solo fueron políticos, sino también diplomáticas. Como señalamos anteriormente, la trayectoria escritural de Bulnes se ajustó al paradigma del historiador que concebía su labor como un servicio diplomático al país, al movilizar el pasado para dirimir controversias limítrofes con los países vecinos o bien para defender la reputación internacional de la nación. En ese sentido, no resulta sorprendente que Guerra del Pacífico haya sido utilizada no solo por la opinión pública, sino también por las dirigencias nacionales para aportarle solidez histórica a la posición chilena en medio de los diferendos diplomáticos por Perú por la ejecución del Tratado de Ancón y el eventual plebiscito que pondría fin a la cuestión de la soberanía de las provincias de Tacna y Arica, el gran dilema territorial por resolver tras el fin de la guerra. La portada de Sucesos del 30 de julio de 1914, ilustrada por Carlos Wiedner en donde la musa Clío porta en sus brazos un ejemplar de Guerra del Pacifico y con la "luz de la historia" procede a cegar con sus destellos a los vecinos de Chile representados de manera racializada-un indígena, a Bolivia; un gaucho, a Argentina; y un afrodescendiente, al Perú- es elocuente de este tipo de utilizaciones del libro de Gonzalo Bulnes.

64 Rodríguez Mendoza, 1929: 248-256. 


\section{\begin{tabular}{l|l} 
Cuadernos de Historia. Serie economía y sociedad & 26/27: pp.209-240
\end{tabular}}

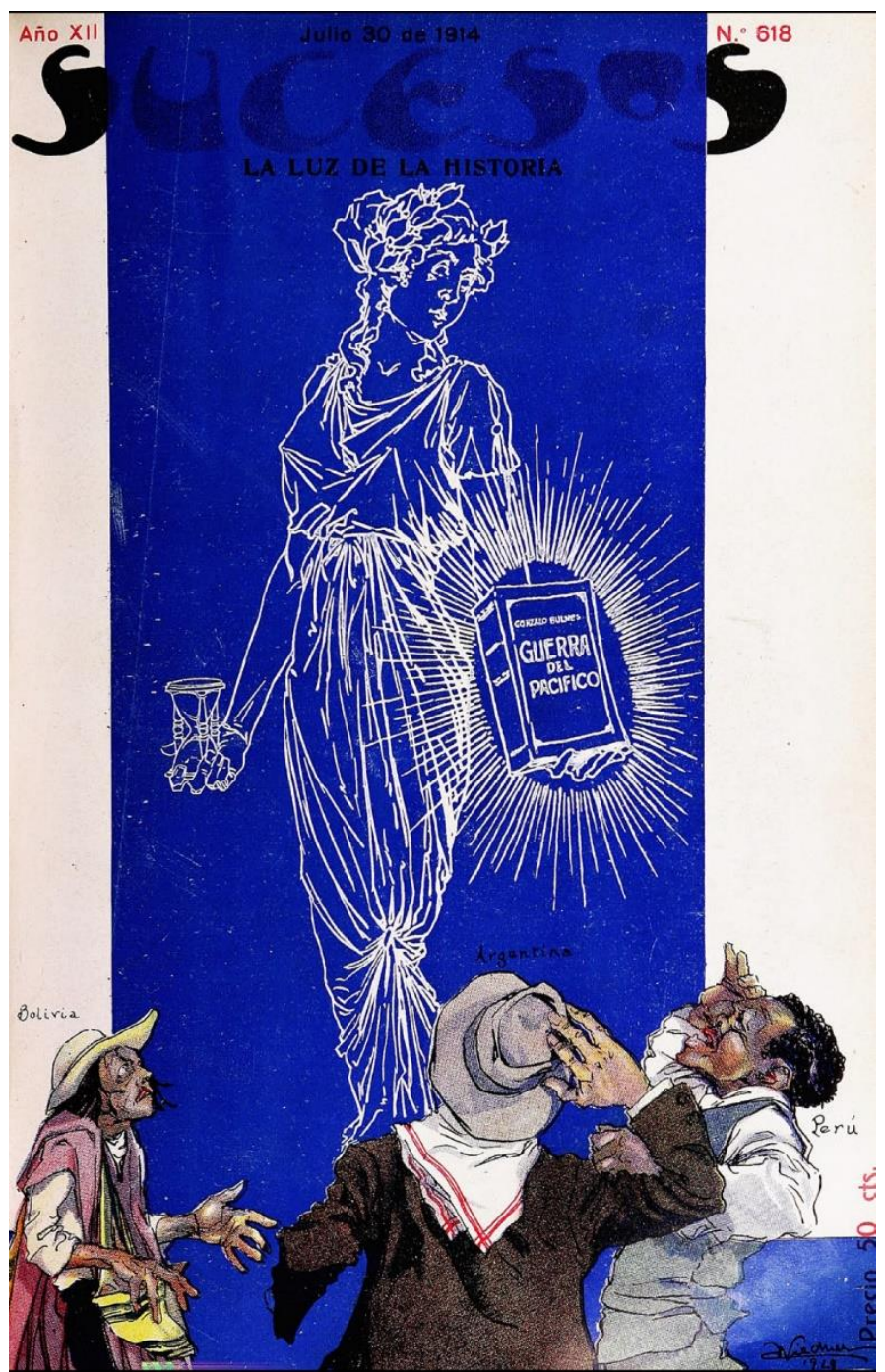

Imagen 3. Carlos Wiedner. "La luz de la historia", Sucesos, 30 de julio de 1914.

El fin de la Primera Guerra Mundial y los intentos de reconfiguración del orden mundial liderados por la figura del presidente de EE.UU. Woodrow Wilson, contribuyeron a actualizar las negociaciones por la cuestión de Tacna y Arica desde la perspectiva peruana. En efecto, la diplomacia peruana intentó conseguir la mediación de Washington para solucionar su diferendo con Chile e impulsó la instalación de este problema en la agenda de la recientemente creada Sociedad de las Naciones. ${ }^{65}$ En dicho escenario, la publicación del volumen final de Guerra del Pacífico a inicios de 1919 adquirió un sentido de actualidad inesperada, pues sus contenidos abordaban el

65 González Miranda, 2008: 63-64. 
período de la ocupación chilena y las tratativas diplomáticas para poner fin a las hostilidades, las mismas que se habían extendido por más de cuatro décadas. Instalado a esas alturas como una figura reconocida a nivel continental, la opinión de Bulnes sobre estos asuntos se volvía clave en el debate diplomático. Así, el periódico bonaerense La Nación recabó su impresión sobre el diferendo diplomático sobre las provincias de Tacna y Arica y una eventual solución plebiscitaria. Bulnes, recientemente designado por Chile como embajador en Argentina, era una voz autorizada, especialmente tras haber realizado "prolijos estudios sobre la contienda de la cual es derivación el pleito que se debate abora, estando a punto de terminar una obra de investigación histórica muy importante, titulada La Guerra del Pacifico”. El historiador, agregaba el medio, es "uno de los hombres más destacados de su país", "uno de los hombres más prominentes de Chile". ${ }^{6}$ En la opinión de Bulnes, la idea del plebiscito pactada en Ancón era solo una forma de "suavizar" la idea de venta de Tacna y Arica a Chile. El plebiscito era una formalidad, "que no cambiaba la esencia de las cosas, para que el pueblo peruano conservase la ilusión de que esos territorios no estaban cedidos ni vendidos". El estudio de la documentación diplomática inédita de los sucesos que recabó para la elaboración del último volumen de Guerra del Pacifico lo llevaba a esa conclusión. Perú no poseía derecho "para pretender que el plebiscito se realice en forma que le asegure una votación dada", declaraba tajantemente, y agregaba: "esta es la verdad escrita, la verdad que ha herido mi conciencia de bistoriador y que debo respetar, aunque antes haya pensado de otro modo". ${ }^{67}$

El avance mediático de la posición peruana, que para forzar la mediación internacional de su diferendo con Chile mostraba a éste como un país expansionista que se había apropiado por medios ilegítimos de territorios claves, en un escenario internacional que cuestionaba las anexiones bélicas, impulsó a Bulnes - a instancias del gobierno a dar a la luz una versión resumida de su libro. En este debía dejar en claro la justicia de la causa chilena y que, a diferencia de lo que sostenía la posición peruana, mostraba a Chile como una víctima de las conjuraciones diplomáticas de sus vecinos. Ese fue el propósito de Las causas de la guerra entre Chile y el Perú, publicado en 1919. Concebido explícitamente tanto como una síntesis de la obra mayor de Bulnes, como un resumen

66 La Nación, Buenos Aires, 21 de diciembre de 1918.

67 Bulnes, 1919a: 60-62. 
de las relaciones internacionales entre ambos países, el nuevo libro del historiador chileno buscaba poner el acento en la ilegítima actitud boliviana que violentaba los acuerdos limítrofes de 1866 y 1874 que regulaban la actividad económica salitrera en el desierto de Atacama y, sobre todo, la perfidia del tratado secreto de 1873. Éste, aprovechando la ausencia de poder naval en Chile, reduciría al país a su mínima expresión: Bolivia extendería sus fronteras hacia el sur del desierto; Perú lograría el monopolio salitrero una vez liquidada la actividad económica chilena en la zona y Argentina lograría hacerse con la Patagonia. "Nunca corrió Chile mayor peligro, ni se eligió mejor el momento para dejarlo reducido a aquel sobrante que no le interesaba a ninguno de los complotados", sentenciaba Bulnes. ${ }^{68}$ A inicios de 1879 el Presidente Aníbal Pinto, aclaraba, en su "exaltación pacífica" intentó por todos los medios de evitar el conflicto, aún conociendo el Tratado de 1873. En síntesis, señalaba el historiador, la evidencia documental y la comprensión adecuada de los antecedentes diplomáticos del conflicto de 1879 debían dejar en claro que en ninguna circunstancia la guerra "fue una celada preparada por Chile para apoderarse de Tarapacá y del litoral boliviano". Por el contrario, "en realidad fue una guerra preparada por el Perú en 1873; aceptada y decidida por él en febrero de 1879, resistida y fuertemente combatida entre nosotros por hombres que actuaban al frente del Gobierno, en la primera línea de la política y la sociedad'. ${ }^{69}$

Meses después, esta obra fue traducida el inglés - bajo el título algo diferente de Chile and Peru. The causes of the war of $1879-{ }^{70}$ para facilitar su circulación a nivel internacional, especialmente para impactar en círculos diplomáticos e instalar allí la visión chilena de los sucesos. Así, en julio de 1920 la cancillería chilena envió a la Liga de las Naciones un par de ejemplares de la versión inglesa de la obra de Gonzalo Bulnes, para que circulase entre sus miembros y estuvieran al tanto de la tesis chilena en medio del recrudecimiento de las tensiones diplomáticas por las regiones de Tacna y Arica. ${ }^{71}$

Tal era el propósito de Bulnes con su obra: no solo reivindicar la justicia de la causa chilena y desmentir su imagen de país expansionista, sino también restarle legitimidad a la fórmula plebiscitaria como mecanismo de resolución de los conflictos fronterizos

68 Bulnes, 1919b: 49.

69 Bulnes, 1919b: 134.

70 Bulnes, 1920.

71 United Nations Archive, Geneva, Records and Archives Unit, League of Nations Secretariat, R543/11/5299/12. 
entre Chile y Perú. La aparición de otro extracto de su libro en 1919, bajo el título de La soberanía definitiva de Tacna y Arica, a la luz de la bistoria de la Guerra del Pacifico, vino a reivindicar el uso de su obra magna como un insumo decisivo de la posición chilena en la época. ${ }^{72}$ Con base a esas indagaciones, la voz de Bulnes fue requerida con frecuencia para pronunciarse respecto a la resolución del conflicto limítrofe. En 1922, por ejemplo, en una entrevista concedida al intelectual Armando Donoso, Bulnes insistió en que la justicia de la causa chilena demandaba una pronta y pacífica resolución del conflicto de Tacna y Arica, calificada de una verdadera "espina en el pie, una amenaza para la tranquilidad de los pueblos vecinos". "No es posible que mantengamos a la América pendiente de este asunto: el continente quiere paz estable, sin ninguna nube en el horizonte", añadía. ${ }^{73}$ E insistía en la tesis levantada en el tercer volumen de Guerra del Pacifico: que la naturaleza del Tratado de Ancón era la entrega de ambas regiones a Chile, y que el plebiscito solo intentaría camuflar la intención original de sus negociadores. Lo que quedaba era que Perú desistiera de su actitud en el concierto internacional - "vive en una situación que no es honrosa: con el sombrero en la mano ante las grandes naciones, en demanda de su ayuda" - y que entre ambos países construyesen una "política de concordia, de comercio $y$ de armonía". ${ }^{74}$

\section{Reflexiones finales}

En este trabajo he examinado el vínculo entre historiografía, guerra y nacionalismo. Esta conexión tuvo en la figura de Gonzalo Bulnes un cultor destacado, en tanto construyó su carrera como historiador enfocándose en los conflictos bélicos que el Estado chileno peleó en el siglo XIX - la Independencia, la Guerra contra la Confederación y la Guerra del Pacífico -, guerras que desde su perspectiva habían contribuido a lograr la libertad nacional, a consolidar su autonomía, a expandir su territorio, a fortalecer la institucionalidad estatal, a diseminar entre la población el sentimiento nacional y posicionar a Chile como una potencia continental. Mediante una comprensión de su oficio que lo presentaba como el garante de la verdad del

72 Bulnes, 1919c.

73 Donoso, 1947: 285.

74 Donoso, 1947: 286. 
pasado mediante su sólida reconstrucción documental, Bulnes concibió a la historia como una disciplina que desentrañaría los patrones ocultos y permanentes del devenir de la nación, develando su excepcionalidad en el concierto hispanoamericano.

Tales discursos sobre el impacto de los conflictos bélicos en la vida nacional encontraron un contexto de recepción muy favorable a inicios del siglo XX, momento en el que Bulnes elaboró su Guerra del Pacífico. La misma noción instalada en su libro, de que el país nunca había sido más grande que en el conflicto que enfrentó en 1879, y que esa constatación imponía un modelo de conducta e inspiración cívica a las generaciones presentes, encontró un auditorio proclive a asumir tales discursos históricos. En efecto, pese a que el conflicto había terminado hacía décadas, la Guerra del Pacífico se había constituido a esas alturas, gracias a un persistente despliegue ritual, conmemorativo, escultórico, educacional, literario y museográfico, en un episodio crucial para el imaginario colectivo chileno, poseyendo un atractivo permanente que dotaba de orgullo y de exaltación patriótica a la audiencia local. Tanto este legado como los diferendos limítrofes aún irresueltos con Perú proporcionaron a la guerra de 1879 una sorprendente actualidad. Ese vacío vino a llenar el trabajo en tres volúmenes de Gonzalo Bulnes, que por espacio de una década satisfizo las demandas del auditorio chileno de poseer una nueva narración que explicase los triunfos de la nación y las vicisitudes de aquel momento que se convirtió en el punto cúlmine de la trayectoria patria en el siglo XIX. La nostalgia de aquellos años, conceptualizados como la "edad dorada" de la nación, fue un sentimiento que la obra de Bulnes contribuyó a movilizar, sintonizando con las corrientes nacionalistas dominantes de la época y con la crítica al régimen parlamentario de inicios del siglo XX. Porque su libro no solo supuso un hito historiográfico en la literatura chilena y en la disciplina, sino que devino en un insumo clave - como lo demuestran las diversas lecturas que se hicieron de éste - para cuestionar el presente apelando a aquel pasado idealizado. 


\section{FUENTES}

\section{Inéditas}

United Nations Archive, Geneva, Records and Archives Unit, League of Nations Secretariat, R543/11/5299/12.

\section{Éditas}

Bulnes, G. 1878, Historia de la campaña del Perú en 1838, Imprenta Los Tiempos, Santiago.

Bulnes, G. 1887, Historia de la Espedicion Libertadora del Perú (1817-1822), Rafael Jover, Santiago.

Bulnes, G. 1897, Últimas campañas de la Independencia del Perú (1822-1826), Imprenta Barcelona, Santiago.

Bulnes, G. 1898, Chile i la Arjentina. Un debate de 55 años!, Imprenta Barcelona, Santiago.

Bulnes, G. 1907, "Barros Arana en la intimidad" en El Mercurio, Santiago, 7 de noviembre.

Bulnes, G. 1911, "El discurso del señor Alfonso en la Cámara de Diputados" en El Mercurio, Valparaíso, 22 de agosto.

Bulnes, G. 1911-1919, Guerra del Pacífico, Imprenta y Litografía Universo, Valparaíso.

Bulnes, G. 1919a, "De don Gonzalo Bulnes" en VV.AA. El problema de Tacna y Arica. Encuesta de "La Nación" de Buenos Aires, Imprenta Universitaria, Santiago, pp. 57 a 62.

Bulnes, G. 1919b, Las causas de la guerra entre Chile y el Perú, Imprenta y Litografía Barcelona, Santiago.

Bulnes, G. 1919c, La soberanía definitiva de Tacna y Arica, a la luz de la bistoria de la Guerra del Pacifico, Imprenta Universitaria, Santiago.

Bulnes, G. 1920, Chile and Peru. The causes of the War of 1879, Imprenta Universitaria, Santiago.

Cruchaga Tocornal, M. 1936, "Quiso a la historia sobria y franca, como sobrio y franco fue su carácter" en ElMercurio, Santiago, 19 de agosto.

Donoso, A. 1947, Recuerdos de cincuenta años, Nascimento, Santiago.

Guevara, T. 1914, "Historia de la Guerra del Pacífico, por don Gonzalo Bulnes" en El Mercurio, Santiago, 19 de julio.

Pantoja Cerda, S. 1936, "La última entrevista a don Gonzalo Bulnes" en La Nación, Santiago, 18 de agosto.
Pinochet Le Brun, T. 1914, "Extensión universitaria de la Asociación de Educación Nacional. Conferencia dada en el Teatro Municipal sobre la Escuela de Artes y Oficios" en ElMercurio, Santiago, 23 de diciembre.

Rocuant, M. L. 1911, "Don Gonzalo Bulnes” en Selecta, Santiago, octubre de 1911.

Rodríguez Mendoza, E. 1929, Como si fuera ahora... Nascimento, Santiago.

Rodríguez, J. M. 1914, "D. Gonzalo Bulnes, íntimo” en Sucesos, Valparaíso, 23 de julio.

Sociedad Chilena de Historia y Geografía, 1915. "Sesión general celebrada por la Sociedad Chilena de Historia y Geografía el 27 de diciembre de 1914, con el objeto de hacer entrega al señor don Gonzalo Bulnes de la medalla anual de oro de la Sociedad" en Revista Chilena de Historia y Geografía, Núm. 17, pp. 5 a 16.

Valdés Vergara, F. 1911, "Suplemento a la sección bibliográfica. Guerra del Pacífico. De Antofagasta a Tarapacá, por Gonzalo Bulnes" en Anales de la Universidad de Chile, Núm. 129, pp. 453 a 476.

Vicuña Mackenna, B. 1936, "Historia de la campaña del Perú en 1838 por Gonzalo Bulnes" en Revista Chilena de Historia y Geografía, Núm. 81, pp. 24 a 35.

\section{BIBLIOGRAFÍA}

Brahm, E. 2002, Preparados para la guerra. Pensamiento militar chileno bajo influencia alemana 1885-1930, Ediciones Universidad Católica de Chile, Santiago.

Cid, G. \& San Francisco, A. (eds.) 2010, Nacionalismos e identidad nacional en Chile. Siglo $X X$, Centro de Estudios Bicentenario, Santiago.

Cid, G. 2011, La Guerra contra la Confederación. Imaginario nacionalista y memoria colectiva en el siglo XIX chileno, Ediciones Universidad Diego Portales, Santiago.

Collier, S. 1977, "The Historiography of the 'Portalian' period (1830-1891) in Chile" en Hispanic American Historical Review, Vol. 57, Núm. 4, pp. 660 a 690.

Corvalán Márquez, L. 2009, Nacionalismo y autoritarismo durante el siglo XX en Chile. Los orígenes, 1903-1931, Ediciones Universidad Católica Silva Henríquez, Santiago.

Donoso, C. 2012, “Tarapacá, territorio de ocupación (1879-1883)" en Boletín de la 
\begin{tabular}{r|r} 
G. Cid & 26/27: pp.209-240 \\
Cuadernos de Historia. Serie economía y sociedad &
\end{tabular}

Academia Chilena de la Historia, Núm. 121, pp. 97 a 131 .

Gazmuri, C. 2001, El Chile del Centenario, los ensayistas de la crisis, Instituto de Historia UC, Santiago.

Gazmuri, C. 2006, La historiografia chilena (18421920), Taurus, Santiago.

González Miranda, S. 2008, La llave y el candado. El conflicto entre Perú y Chile por Tacna y Arica, Lom/ USACH, Santiago.

Hartog, F. \& Revel, J. (Dirs.) 2001, Les ussages politiques du passé, Editions de L'École des Hautes Études en Sciences Sociales, Paris.

Hobsbawm, E. 1992, "Ethnicity and Nationalism in Europe Today" en Anthropology Today, Vol. 8, Núm. 1, pp. 3 a 8.

Ibarra, P. 2018, "La victoria de la 'nación en armas': Gonzalo Bulnes y la Guerra del Pacífico" en Ibarra, P. \& Morong, G. (Eds.) Relecturas de la Guerra del Pacifico: avances y perspectivas, UBO Ediciones, Santiago, pp. 269 a 300.

Lawrence, P. 2013, "Nationalism and Historical Writing" en Breuilly, J. (Ed.) The Oxford Handbook of History of Nationalism, Oxford University Press, Oxford, pp. 714 a 731.

Levinger, M. \& Franklin, P. 2001, "Myth and Mobilisation: The Triadic Structure of Nationalist Rhetoric" en Nations and Nationalism, Vol. 7, Núm. 2, pp. 175-194.

Marín, R. 1940, Don Gonzalo Bulnes, Imprenta Letelier, Santiago.

Millar, R. 1972-1973, "Significado y antecedentes del movimiento militar de 1924" en Historia, Núm. 11, pp. 7 a 102.

Nunn, F. 1970, "Emil Körner and the Prussianization of the Chilean Army: Origins, Process, and Consequences, 1885-1920" en Hispanic American Historical Review, Vol. 50, Núm. 2, pp. 300 a 322.

Ossa, J. L. 2005, “Gonzalo Bulnes y su Historia de la campaña del Perú en 1838" en Seminario Simon Collier 2005, Instituto de Historia UC, pp. 195 a 222.

Ossa, J. L. 2013, “Gonzalo Bulnes: historiador nacionalista, político civilista" en Estudios Públicos, Núm. 132, pp. 171 a 200.

Quiroga, P. \& Maldonado, C. 1988, El prusianismo en las fuerzas armadas chilenas. Un estudio bistórico 1885-1945, Documentas, Santiago.

Rubilar, M. 2015, “La 'Prusia americana': prensa argentina e imaginario internacional de
Chile durante la Guerra del Pacífico (18791881)" en Revista de Historia y Geografía, Núm. 33, pp. 83 a 121.

Sater, W. F., 2005, La imagen heroica en Chile: Arturo Prat, santo secular, Centro de Estudios Bicentenario, Santiago.

Smith, A. D. 1992, "Nationalism and the Historians" en International Journal of Comparative Sociology, Núm. 33, Vol. 1-2, pp. 58 a 80.

Subercaseaux, B. 2007, Historia de las ideas y de la cultura en Chile. Tomo IV: Nacionalismo y Cultura, Editorial Universitaria, Santiago.

Woll, A. 1982, A Functional Past. The Uses of History in Nineteenth-Century Chile, Louisiana State University Press, Baton Rouge.

Yaeger, G. 1981, Barros Arana's Historia jeneral de Chile: Politics, history, and national identity, Texas Christian University Press, Fort Worth. 